\title{
An efficient microcontroller based sun tracker control for solar cell systems
}

\author{
E.M.H. Arif, J. Hossen, G. Ramana Murthy, Jesmeen M. Z. H., J. Emerson Raja \\ Faculty of Engineering and Technology, Multimedia University, Malaysia
}

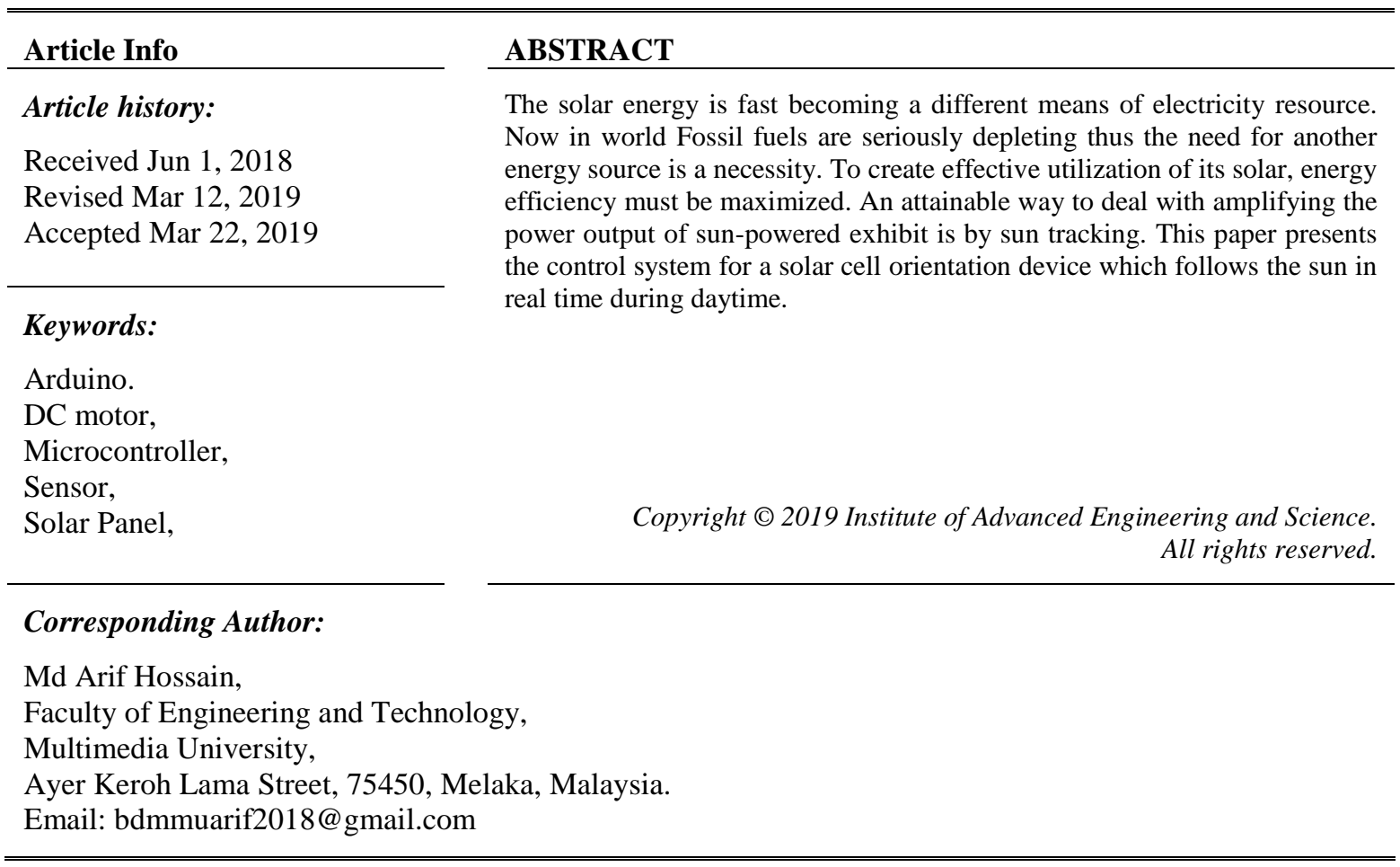

\section{INTRODUCTION}

The global warming problem has at present drawn world-wide public consideration to issues connected to energy preservation and alternate energy. A few energy preservation strategies, for example, energy, reusing and energy collecting procedures, have been proposed to lessen pointless vitality squander from commercial apparatus. What's more, elective energy, for example, wind, warm or sunlight based energy is renewable and addresses pollution issues. The solar energy introduces the benefits of low cost and contamination free qualities [1]. These are keys to comprehending compounding a global calamity crisis and decreasing ozone harming substance emanations. Along these lines, this renewable energy has been increasing expanding prevalence in various nations. Solar based energy in future to may be the most proficient decision as to energy generation. However, despite everything it exceeds different sorts of energy, for example coal, atomic, and gas, energy, since it causes zero contamination, and takes into consideration simple upkeep.

In fossil fuel reserves day by day is very depleting and Price of fossil fuels is increasing very fast. This energy is very affected for our health, air population, environment, emission of the greenhouse [2]. So in the future, need several thoughts for electric energy. Some researchers they are getting alternative way for clean energy development. They are getting renewable energy (solar energy, wind energy, bio-mass energy) sources. So, solar energy is considered as one of the best renewable energy sources [3]. In solar energy the solar panel tracking system plays an important role in achieving maximum efficiency in solar power generation [4]. The sun tracker controls for solar cell systems plays an important role in achieving maximum efficiency in solar power generation [5]. The sun tracking systems needs an efficient controller and a stepper motor to maximize the power output from the solar panels. This Sun tracker control of solar cell systems, the process is occupied superior-intensity power [6]. The Sun - tracking system plays an important role in the development of solar energy applications, especially for the high solar concentration systems that directly convert the solar 
energy into thermal or electrical energy [7]. High level of sun-following exactness is required to guarantee that the solar collector based authority is equipped for outfitting the high solar energy for the duration of the day [8]. The solar power, high focus systems, solar cell plate, cell channel, central receiver system, etc. is the solar energy collecting is very simple [9]. With a specific end goal to keep up high output power and soundness of the solar power framework, a high-exactness sun-following framework is important to take over the sun's direction from first light until nightfall [10].

One of the main advantages of solar cell systems is that they convert light energy delivered by the sun into electrical energy, without harming the environment [11]. In order to maximize their efficiency, they must always be perpendicular to the sun rays during daytime. A schematic solar tracker system is presented in Figure 1. It is a controlled device which can rotate in a horizontal plane (zenith rotation) on a turntable actuated by the motor 2 and also in the vertical plane (azimuth rotation) actuated by the motor 1. Both electric motors can be either DC motors or stepper motors.

Thus, in this system, automatic changing the route to do the superior strength of light [12]. In this tracking system, they have used LDR sensor, motor devices for four ways to the feeling of the superior intensity of sunlight. And it will be procedure the input voltage as the solar panel with control the instructions in which motor has to rotate so that it resolves to be collect high-intensity light as the sun. So, in recent years researcher proposed the use of different type of controller for the tracking system to achieve superior performances. But there controller results are not considerable. Among this paper, the author doing the proposing "microcontroller" for the sun tracker control for solar cell systems process to provide better performance. In this paper discuss the development of the tracking systems. The performance of this controlled study of simulation and compared with the "analogue controlling device" are discussed. Microcontroller can do easily low time required for performing the operation, processor chips are very small and flexibility occurs, due to their higher integration [13], cost and size of the system are reduced, and at the same time many tasks can be performed so controller effect can save.

In this paper is arranged as follows a brief explanation of the 2 analogue control system and 3 microcontroller control systems. In section 4 results and discussion. In section 5 conclusions.

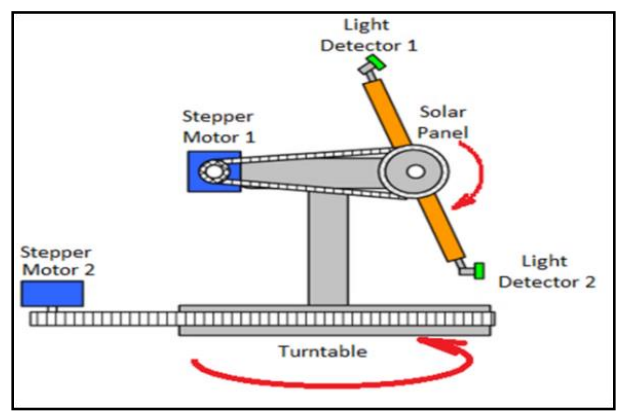

Figure 1. Functioning principle of a solar tracking system

\section{ANALOGUE CONTROL SYSTEM}

In order to generate the tracking movement, the principle presented in the block diagram in Figure 2 is usually used. It can be seen that the control system is composed of a sensor zone, in which light-sensitive devices mounted in pairs can be used, such as LDRs (light-dependent resistors), phototransistors, etc. The signals offered by the sensors are then compared to each other in a comparator block made either with analogue devices or with microprocessors [14]. The output signal of the comparator is used to drive a motor (DC or stepper motor). As long as the signal levels offered by the light sensitive devices are not equal, the control system will keep moving the motor toward the direction indicated by the lowest value of light.

In shown Figure 3 Schematic diagram of an analogue device tracker control system is presented. LDR1 and LDR2 are light sensors IC1 and IC2 are comparators and T1-T4 are the H-bridge used to actuate the DC motor M. P1, R1, P2, R2 are used to fix the input levels (or the voltage window) on which the comparator will start to command the motor driver. At the moment when the LDRs will get the same amount of light, the P1 and P2 must be adjusted in such way that the motor should be still in static position. When LDR2 receive less light than LDR1 then the voltage at point A is greater than the half of the supply voltage. This means that the output of IC1 is in HIGH state, thus allowing transistors $\mathrm{T} 1$ and $\mathrm{T} 4$ to be in conduction state, so that the motor is rotating [15]. Transistors must be chosen in respect to the power absorbed by the motor. For values up to 300mA, T1 and T3 can be of BD239 type or similar, while T2 and T4 can be of 
complementary type, BD240. Diodes D1 to D4 are used as transistor protection against inductive current peaks generated by the motor. For higher values of the power (current) absorbed by the motor, a pair of $2 \mathrm{~N} 3055 / \mathrm{MJ} 2955$ transistors can be used. If the driving current offered by the ICs is not enough to drive the bridge, they can be used in Darlington montage together with BD239/BD240. Sensors must be mounted in a device similar to the one presented in Figure 4.

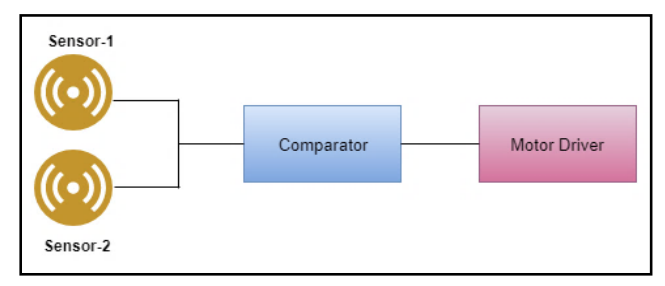

Figure 2. Block diagram of a control system for solar tracker

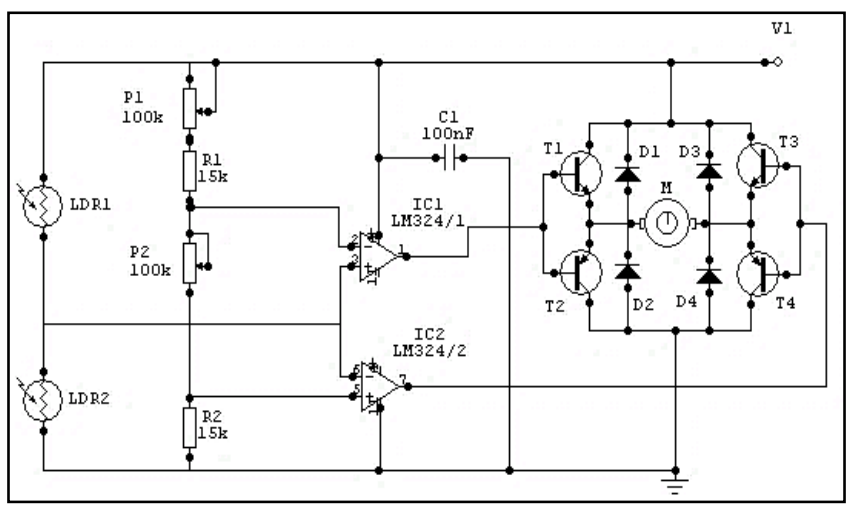

Figure 3. Schematic diagram of an analogue device tracker control system

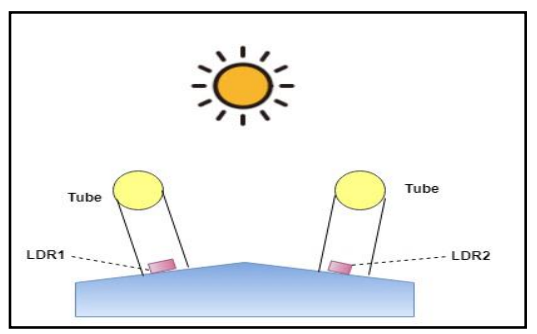

Figure 4. Sensor mounting device

As it can be seen the shape of the mounting device must avoid direct sunlight on the sensors when the system is perpendicular to the rays. This can be accomplished by using non-reflecting black tubes and an inclined surface of the geometry where sensors are mounted [16]. The height of the tubes must also be enough to keep LDRs away from the sunlight when the device is properly oriented. In order to allow azimuth and zenith movements, two identical control systems must be used one for horizontal (zenith) rotation, and one for vertical (azimuth) rotation. Sensors must be properly mounted, one set for horizontal movement and one set for vertical movement [17].

\section{MICROCONTROLLER CONTROL SYSTEM}

The control system uses microprocessors to mainly replace the analogue comparator with a microprocessor and driving software. A huge advantage of these systems is that it allows much precise positioning and also controls other aspects of energy accumulation using microprocessor capabilities. Another advantage is that it can be programmed to orient itself in the eastern direction at the moment when night appears, in order to "wait" prepared for the rising sun next day and so on. 
Due to the fact that the microcontroller is able to analyze independently the level of light on each of the LDRs, a simpler sensitive device, using only 3 LDRs can be made. Working principle for 3 LDRs lays on the way in which microcontroller work and on the way in which sensors are mounted as shown in Figure 5: LDR1 and LDR2 are mounted in line in horizontal position. They are used to detect differences between their light levels. If differences occur, the microcontroller will command the motor driver to adjust the position in respect to the vertical axes. When the light level is equal on both LDRs, their mean value is then compared to the light level on LDR3, thus realizing, in a similar manner as presented previously, the positioning of the system around the horizontal axes.

The flowchart for such a system is presented in Figure 6 and is adapted considering a principle mentioned. After initializing sequence system acquires light levels from the sensors. In case the values are lower than a threshold value, it means that outside is not. In this case the system goes to the initial position and waits to the next sunrise. If there is light, the system verifies if the LDR1 and LDR2 have the same level of light. If not, a command is sent to the motor driver to rotate it with one step in the desired position (toward the higher values). This step repeats until light levels are equal on both LDRs and no command is sent to the motor driver.

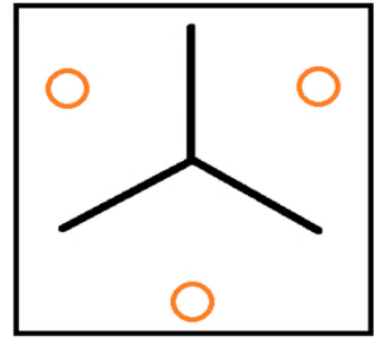

Figure 5. The architecture of Sensor mounting

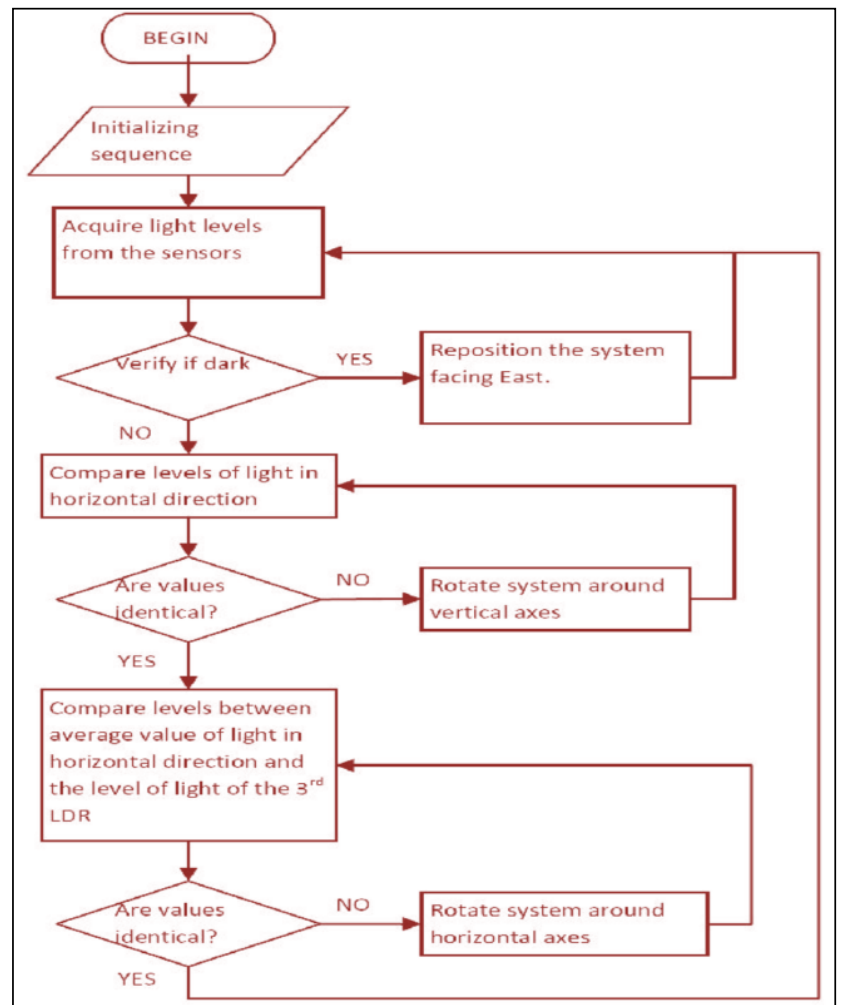

Figure 6. Flowchart for a sun tracker control system using microcontroller

Further, the system calculates the average of LDR1 and LDR2 light levels and compares it to the light level on LDR3. If there is no match, a command is sent to the motor which rotates the solar panel around a horizontal axis with one step, until there are no differences between the average of LDR1 and LDR2 light levels and the light level of LDR3. When all the values are identical, the system returns in initial position and reiterates the process. Schematic diagram of a control system using Arduino UNO is presented in Figure 7. Figure 8 presents a capture of the Arduino program with the function which allows the rotation of the system around its vertical axes. 


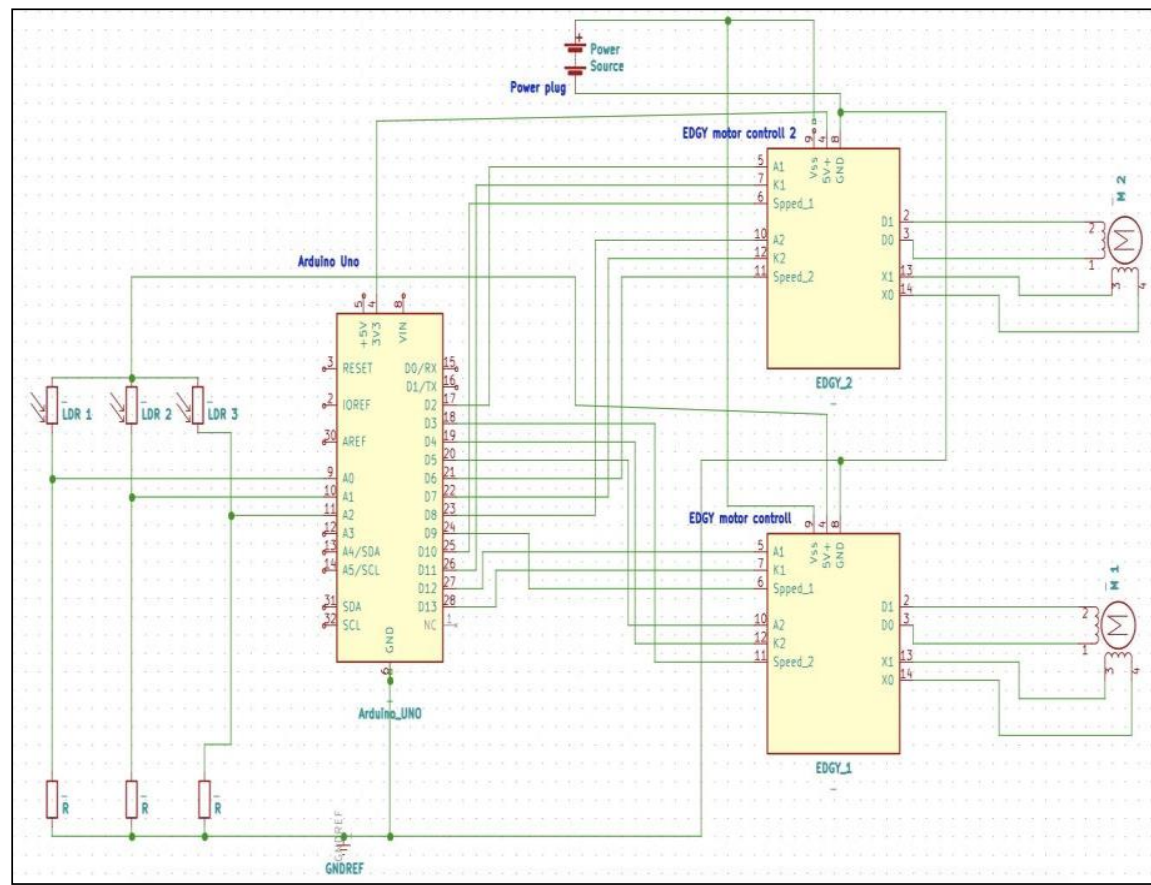

Figure 7. Schematic diagrams for a tracking control system using Arduino Uno

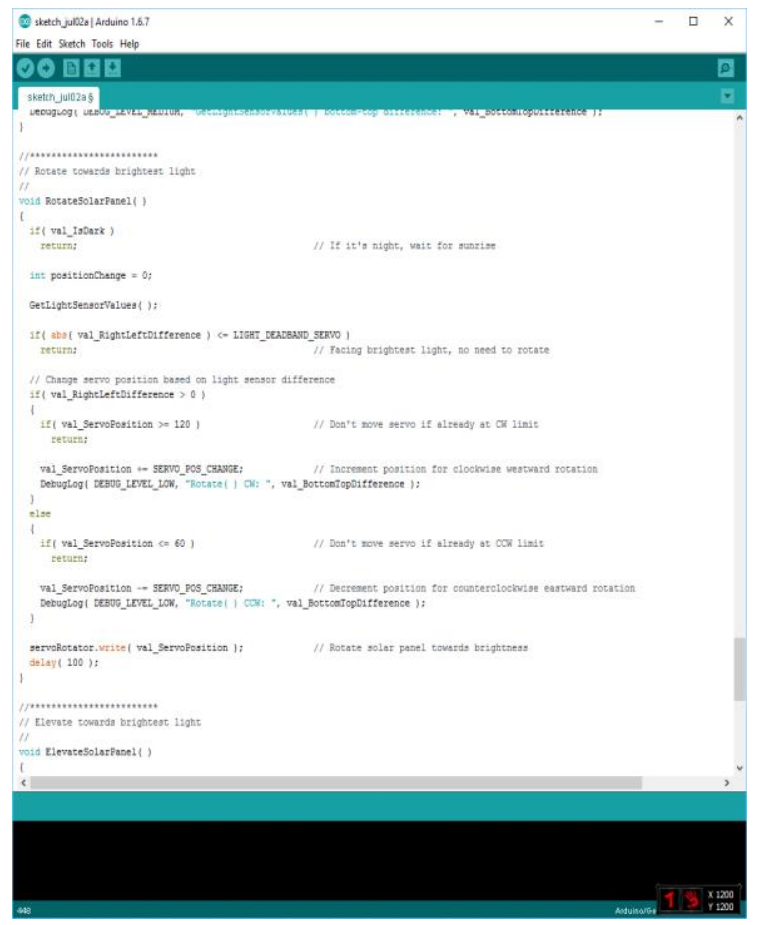

Figure 8. Print-screen of the sketch for Arduino Uno

\section{RESULTS AND DISCUSSION}

With the end goal to exhibit the adequacy of the proposed approach, the composed controller is utilized to track the microcontroller under steady and differing climatic conditions. For every climatic conditions case, a comparative report among proposes the microcontroller is performed for sun tracker control for solar cell systems. The solar based panel following framework is demonstrated and utilizing Arduino, kid cad, Sci-lab condition. In this paper mainly work focuses on the performance of manual and tracker systems. To reach this data, straightforward analyses were performed. In Figure 1 shows the experimental setup for 
fixed and tracker systems. The temperatures amid the trial were recorded utilized the light dependent resistor (LDR) sensor. The open-circuit voltage and the present data reading were recorded utilizing a multi-meter associated with the solar powered cells.

The reproduction aftereffects of the sun based tracker utilizing the Simulink are appearing in Figures 9 and 10. As observe from the plots, the sun based tracker can pursue the sun angle. In the plot, this solar oriented tracker delivers a higher current output when contrasted the settled PV panel. Furthermore, the other piece of the diagram demonstrates the condition of the power efficiency performance. In this system simulation power and current output of the day was quite close to the actual results obtained. At the same system experiment time, there was some slight deviation amid the morning and afternoon time frame because of the demonstrating of the real irradiance acquired from the experiment. The output power of this tracker was compared with the fixed panel design in order to determine the efficiency of the solar tracker system. As expected the average efficiency created by the proposed tracking panel is higher than that of the fixed panel. Here, the output efficiency alludes to the proportion of contrast between the entirety of this tracker and the fixed panel capacity to the total of fixed panel control over the time of interest. In this tracking system the productivity, efficiency (get from exploratory results) is around $28.5 \%$ in Figure 11. As compare to several the solar pane trackers as realized in this paper [14, 18, 19], the average efficiency is good and hence, the proposed design results is higher and comparable to the existing design. As found in Figure 11, the solar panel tracker was productive amid the majority of the day with the exception of amid the early afternoon where the sun irradiance was observed to be the most noteworthy. Hence, the tracking panel system that horizontal and vertical on the ground is in this way much practiced.

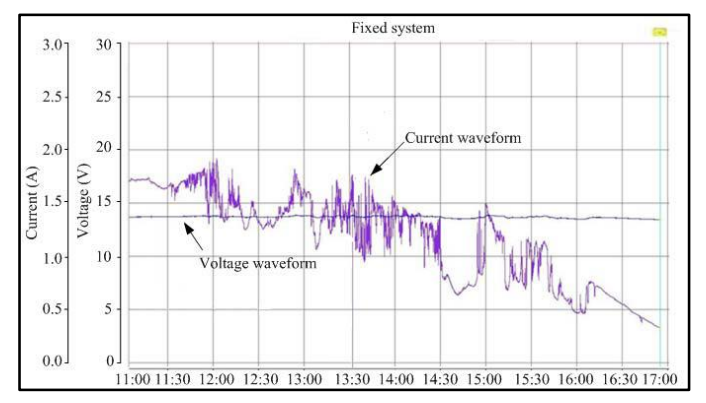

Figure 9. Fixed Solar panel measured time functions of output voltage and current

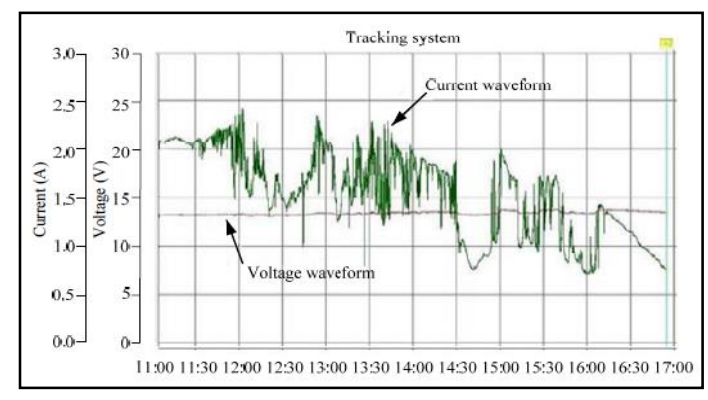

Figure 10. Solar tracking system measured time functions of output voltage and current

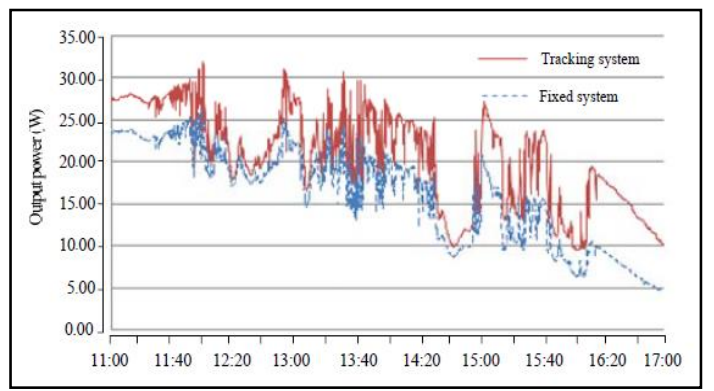

Figure 11. Tracking and fixed systems Comparison of the generating power

For the expense and advantage of the proposed solar based tracker framework, it has some extraordinary example, the underlying use of the materials is typically medium, yet there is no fuel cost included and the upkeep cost is low. The aggregated information [20] demonstrate that at present a solar panel framework is competitive where small amounts of energy are required at a place that is far away from an electric grid or any other source of energy. Our estimates of the electricity cost matched with those reported for the solar cell, diesel generator and grid-extension systems. Our analysis shows that the cost of electricity from a solar cell system is approximately equal to that from a diesel generator and cheaper than a grid extension. This solar system may be used for domestic applications, especially in remote areas. Keeping in view the environmental impact and economic assessments of the designed solar system, it is evident from the listed data that the solar system even at present is a competitive choice for small power requirements. With the expectation 
that the cost of a solar module will reduce in the near future see one of the report from (Solarbuzz.com) on Jan 2018, a solar panel tracking system may as well become an economic and more attractive option for higher loads.

\section{CONCLUSION}

This paper presented a sun tracker control system for solar cell systems: One of them uses a microcontroller device which controls a motor driver realized with discrete components. Regardless of the method used, the system needs light sensors, two for each controlling device. In the case of using a microcontroller, it is possible to use only LDRs. Two identical comparators are needed for the analogue system, while there is sufficient one microcontroller to control both motors. Precision in positioning the solar panel is greater in the case of using a microcontroller due to the fact that stepper motors can be used to actuate the system. The proposed design was simple and self-contained, requires programming and a computer interface. A laboratory has been successfully built and tested to verify the effectiveness of the control. Finally, Experiment results indicated that the developed system increased the tracking system rather than fixed systems.

\section{ACKNOWLEDGEMENTS}

All praise to supreme almighty Allah, whose blessings and kindness. I went to thank and show my deepest gratitude towards the entire faculty member who gives me adequate encouragement and every possible help to complete this work. Finally, I want to thank Erasmus Mundus authority for my research money supporting help.

\section{REFERENCES}

[1] Ferdous Hossain, E.M.H.Arif, Tan Kim Geok, J.Hossen, Sharif Ahmed, Md. Armanur Rahman, Tawsif K., "Self-Sustainable Energy Harvesting System," IEEE Symposium on Computer Applications \& Industrial Electronics (ISCAIE), Page 59-64, 2018.

[2] E.M.H. Arif, J. Hossen, G. Ramana, Thangavel Bhuvaneswari,P. Velrajkumar, C. Venkataseshaiah, "A survey on neuro-fuzzy controllers for solar panel tracking systems," Far east journal of electronics and communications, Volume 18, Number 7, Pages 981-1003, 2018.

[3] C. -S. Chiu and Y. -L. "Ouyang, robust maximum power tracking control of uncertain photovoltaic systems: A uni_ed T-S fuzzy model based approach," IEEE Trans. Control Syst. Technol., vol. 19, no. 6, pp. 1516-1526, Nov. 2011

[4] A.I.B. Ibrahim, F.D.B.A. Rahman, M.B. Rohaizat. "Dual axes solar tracker," International Journal of Electrical and Computer Engineering, VL-8, PP: 1887-1892, 2018.

[5] S. Shanmugasundaram, "Solar Based Z Source Inverter for High Power Application," Bulletin of Electrical Engineering and Informatics, Vol. 6, No. 4, pp. 343 347, Vol. 6, No. 4, December 2017, pp. 343 347, 2017.

[6] Yasmeen H. Sabri, W. Z. Wan. Hasan, S. Shafie, M. A. M. Radzi, A. H. Sabry, "Daily Harvested Energy of Cadmium Telluride Thin Film Photovoltaic," Indonesian Journal of Electrical Engineering and Computer Science, Vol. 11, No. 1, pp. 18-26, July 2018.

[7] Arjyadhara Pradhan, Bhagabat Panda, "A Simplified Design and Modeling of Boost Converter for Photovoltaic System," International Journal of Electrical and Computer Engineering, Vol. 8, No. 1, pp. 141-149 February 2018.

[8] Adel Haddouche, Mohammed Kara, Lotfi Farah, "Maximum Power Point Tracker Using Fuzzy Logic Controller with Reduced Rules," International Journal of Power Electronics and Drive System, Vol. 9, No. 3, pp: 1381-1390, September 2018.

[9] Syafii, Refdinal Nazir, Muhammad Hadi Putra, and Kamsory, "Sensorless Solar Tracker Based on Sun Position for Maximum Energy Conversion," Proceeding of International Conference on Electrical Engineering, Computer Science and Informatics, Palembang, Indonesia, 19 -20 August 2015.

[10] G. G. Raja Sekhar, Basavaraja Banakara, "An Internal Current Controlled BLDC Motor Drive Supplied with PV Fed High Voltage Gain DC-DC Converter,” International Journal of Electrical and Computer Engineering. Vol. 8, No. 2, pp. 1262-127, April 2018.

[11] Sunita Kumari, Sudhir Y. Kumar, "A Novel Approach of Controlling the Solar PV Integrated Hybrid Multilevel Inverter," Indonesian Journal of Electrical Engineering and Informatics, Vol. 6, No. 2, pp. 143-151, June 2018.

[12] Ahmad Saudi Samosir, Herri Gusmedi, Sri Purwiyanti, Endah Komalasari, "Modeling and Simulation of Fuzzy Logic based Maximum Power Point Tracking (MPPT) for PV Application," International Journal of Electrical and Computer Engineering, Vol.8, No.3, pp. 1315 1323, June 2018.

[13] Nurettin Goksenli, Mehmet Akbaba, "Development of a new microcontroller based MPPT method for photovoltaic generators using Akbaba model with implementation and simulation," Solar Energy, Volume 136, Pages 622-628, 15 October 2016.

[14] Jerin Kuriakose Tharamuttam, Andrew Keong Ng, "Design and Development of an automatic solar tracker," Energy Procedia, Volume 143, Pages 629-634, December 2017. 
[15] Masoumeh Abdollahpour, Mahmood Reza Golzarian, Abbas Rohani, Hossein Abootorabi Zarchi, "Development of a machine vision dual-axis solar tracking system," Solar Energy, Volume 169, Pages 136-143, 15 July 2018.

[16] D Chinna Kullay Reddy, S.Satyanarayana, V.Ganesh, "Design of Hybrid Solar Wind Energy System in a Microgrid with MPPT Techniques," International Journal of Electrical and Computer Engineering, Vol.8, No.2, pp. 730 740, April 2018.

[17] A. H. E. Khateb, N. A. Rahim, J. Selvaraj, and B. W. Williams, "DC-to-DC converter with low input current ripple for maximum photovoltaic power extraction," IEEE Trans. IND. Electron., vol. 62, no. 4, Page 22460-2256, April 2015.

[18] Safa Skouri, Abdessalem BenHajAli, SalwaBouadila, Mohieddine Ben Salah, Sassi BenNasrallah, "Design and construction of sun tracking systems for solar parabolic concentrator displacement," Renewable and Sustainable Energy Reviews, Volume 60, July 2016, Pages 1419-1429, 2016.

[19] F_abio Moacir Hoffmann, Rolf Fredi Molz, Jo ao Victor Kothe, Elpidio Oscar Benitez Nara, Leonel Pablo Carvalho Tedesco, "Monthly profile analysis based on a two-axis solar tracker proposal for photovoltaic panels," Renewable Energy, volume 115, page 750-759, 2018.

[20] Karimov KS, Saqib MA, Akhter P, Ahmed MM, Chattha JA, Yousafzai SA., "A simple photo-voltaic tracking system," Solar Energy Materials and Solar Cells, volume 87, Page 49-59, 2005.

\section{BIOGRAPHIES OF AUTHORS}

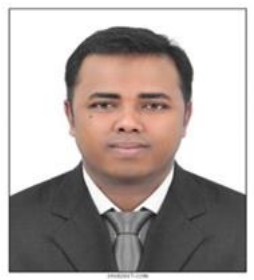

Md Arif Hossain currently a postgraduate student in engineering specialized in solar energy technology from Multimedia University in Malaysia. He has completed bachelor's degree in electrical and electronics engineering from Bangladesh University (B) in Dhaka, Bangladesh in 2013. He is very expert mat lab and Sci-lab. His current research interested in electrical engineering, Renewable energy, wind energy, PID controller, Fuzzy logic controller, Neuro-fuzzy controller, Deep-neuro fuzzy controller, oil, gas and intelligent system.

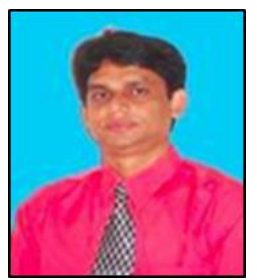

Md Jakir Hossen currently senior lecturer in multimedia university (MMU) and completed Doctor of Philosophy in smart technology and robotics engineering (UPM), Masters in engineering (UPM), Bachelor in Mechanical Engineering (DUET), Diploma in power (Automobile) Engineering (DPI). His research interest is control and robotics, soft-computing (Fuzzy logic and Neuro-fuzzy controller) intelligent system and programing.

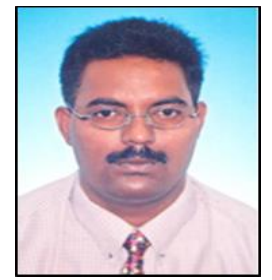

G. Ramana Murthy CEng, MIET, SMIEEE received B.Tech Degree from Nagarjuna University in 1990, M.Tech Degree from G.B.Pant University of Agriculture \& Technology in 1993, and Ph.D. (Engineering) from Multimedia University in 2013. Currently he is working as Senior Lecturer in Faculty of Engineering \& Technology, Multimedia University (Melaka Campus), Malaysia. His main research interests include Analysis and Embedded Computing, VLSI, Nanotechnology, Memory optimization, design and analysis of low-power circuits, FPGA and Evolutionary Algorithms.

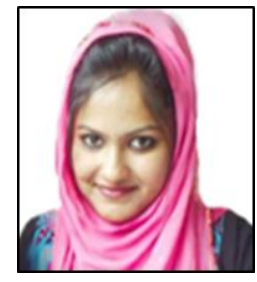

Jesmeen M.Z.H currently a postgraduate student in engineering specialization in artificial intelligence from Multimedia University. She completed bachelor's degree in computer science and engineering from International Islamic University Chittagong, Bangladesh. She is research interested is artificial intelligent, big data, Machine learning.

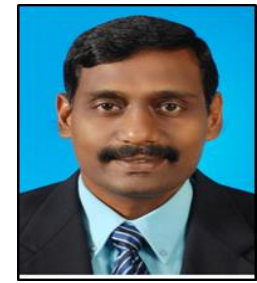

J. Emerson Raja, Ph.D., is currently senior lecturing in the Faculty of Engineering and Technology at Multimedia University, Malaysia. His work is centered on applying soft computing techniques to monitor the health of machines. He has been selected to give lectures in "International Teaching Week" at Hof University of applied sciences, Hof, GERMANY, in June 2013. He had given key note speech in several International Conferences in China and India. His research interested is Soft computing, tool condition monitoring topics and Artificial Intelligent. 